\title{
Sensitivity of Drawdown to Parameters and Its Influence on Parameter Estimation for Pumping Tests in Large-Diameter Wells
}

\author{
by Jiu J. Jiao a and Ken R. Rushton ${ }^{b}$
}

\begin{abstract}
The sensitivity features of drawdown to aquifer parameters and their influence on parameter estimation and pumpingtest design are investigated in terms of pumping tests conducted in a large-diameter well. It is concluded that the well storage reduces the sensitivities of drawdown to transmissivity and storativity, and increases the correlation between them. This leads to uncertainties in estimating the aquifer parameters, especially storativity. The most informative drawdowns in terms of parameter estimation change with time and space. This is instructive for pumping-test design in a large-diameter well. Both hypothetical and real examples are used to demonstrate key ideas.
\end{abstract}

\section{Introduction}

Large-diameter dug wells are used extensively in many parts of the world. When they are used for pumping tests, the water in the well will influence the response of the aquifer. Analytical solutions taking into account the water stored in the well have been developed for confined aquifers by Papadopulos and Cooper (1967) and Lai et al. (1973). An alternative method of investigating pumping tests in a largediameter well is the radial numerical method, which has been successfully used and proved to be much more flexible (Rushton and Holt, 1981). Of principal concern here are the sensitivity of drawdown to aquifer parameters in terms of large-diameter wells and the influence of the well storage on parameter estimation.

Sensitivity features are important in parameter estimation. Information about a physical parameter may be most accurately gained at points in space and time with a high sensitivity to the parameter (Knopman and Voss, 1987). Insensitivity may lead to considerable error in estimating aquifer parameters, and the correlation between parameters may cause difficulties in estimating them independently (McElwee, 1987). Also, a parameter can be best estimated when its sensitivity is not only significant but also changing with time.

Sensitivity analysis of the Theis equation has been examined by McElwee and Yukler (1978). Later, the behavior of sensitivity of parameters in a leaky aquifer has

\footnotetext{
${ }^{2}$ Department of Geology, University of Alabama, P.O. Box 870338, Tuscaloosa, Alabama 35487 U.S.A.

${ }^{\mathrm{b}}$ School of Civil Engineering, University of Birmingham, P.O. Box 363, Birmingham B15 2TT, United Kingdom.

Received April 1994, revised November 1994, accepted December 1994.
}

been investigated by Bohling et al. (1990). However, to the authors' knowledge, no research has been carried out to understand the features of sensitivity of drawdown to parameters when a large-diameter well is involved.

In this paper, the basic sensitivity features of drawdown to aquifer parameters in the Theis equation is first briefly examined for the purpose of comparison. The features of parameter sensitivity relating to a large-diameter well are then discussed by numerical sensitivity models modified from a radial numerical flow model. There are various numerical models available. The one developed by Rushton and Chan (1976) is chosen for this study because their model includes well storage by introducing a portion of the aquifer that represents the region within the well. This is achieved by setting the transmissivity to a very high value to simulate the horizontal water level in the well, while the storage coefficient is set to unity, thereby representing the free water in the well (Rushton and Holt, 1981).

The general sensitivity features of drawdown to aquifer parameters and well storage are examined by a hypothetical example. A real pumping test in a large-diameter well is then used to demonstrate the application of sensitivity features in pumping-test design and analysis in such a well.

\section{Theoretical Background \\ Sensitivity and Normalized Sensitivity}

Sensitivity analysis is the study of a system's response to various disturbances. In this study, the disturbances of aquifer parameters and well storage are considered. The response of the aquifer system may be expressed in terms of drawdown or hydraulic head. Because pumping-test analysis is of particular concern, drawdown is used. Mathematically, the sensitivity is a partial derivative which represents the change in head or drawdown resulting from a change in 
a model parameter. The sensitivity of drawdown to $T$ and $S$ can be defined as:

$$
\begin{aligned}
& \mathrm{U}_{\mathrm{T}}=\frac{\partial \mathrm{s}}{\partial \mathrm{T}} \\
& \mathrm{U}_{\mathrm{S}}=\frac{\partial \mathrm{s}}{\partial \mathrm{S}}
\end{aligned}
$$

where $U_{\mathrm{T}}$ and $\mathrm{U}_{\mathrm{S}}$ are called sensitivity coefficients, or simply sensitivity, with respect to transmissivity (T) and storativity (S).

A marked disadvantage of the sensitivities defined by equations (1) and (2) is that their magnitudes depend on the dimensions and units of the particular parameters. A concept of normalized sensitivity was introduced by McElwee (1987), the sensitivity coefficients being multiplied by the corresponding parameter values. The normalized sensitivities of transmissivity $U_{T}^{\prime}$ and storativity $U^{\prime}$, for example, are thus defined as:

$$
\begin{aligned}
& U_{T}^{\prime}=T \frac{\partial s}{\partial T}=\frac{\partial s}{\partial T / T} \\
& U_{S}^{\prime}=S \frac{\partial s}{\partial S}=\frac{\partial s}{\partial S / S}
\end{aligned}
$$

The second form shown for each sensitivity coefficient demonstrates that normalized sensitivities describe the influence of ratio changes in parameters. Thus, normalized sensitivities can be readily plotted together and compared.
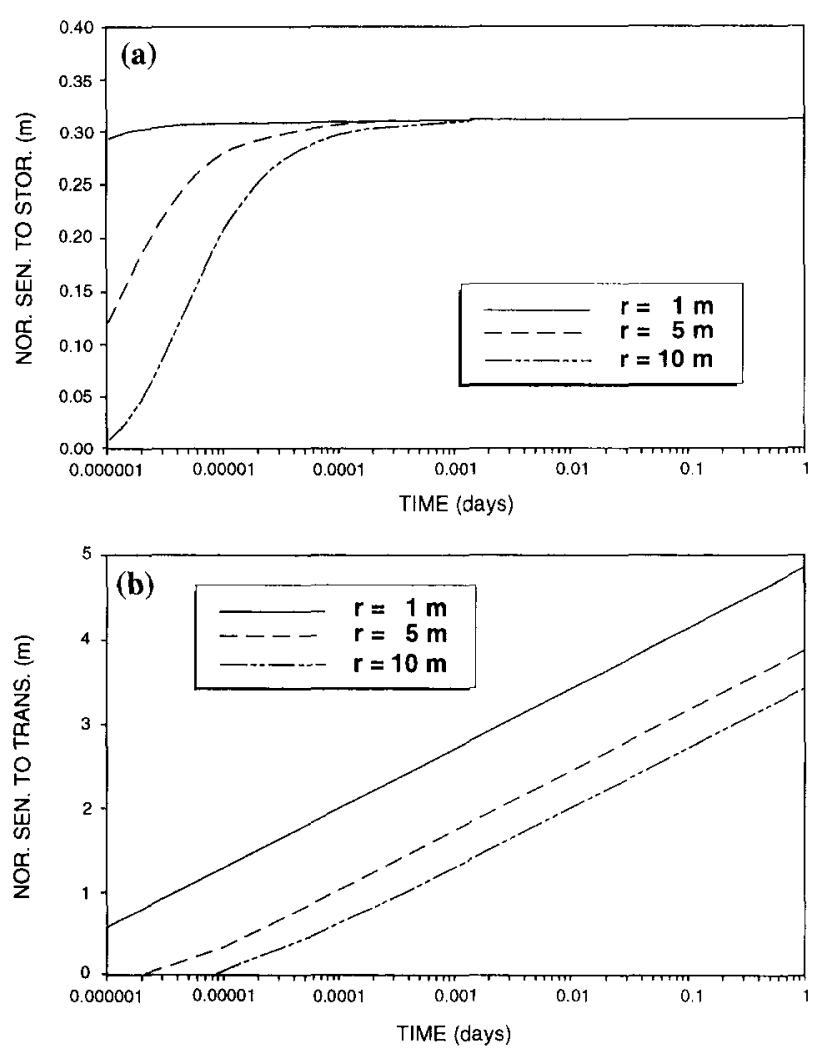

Fig. 1. Temporal change in normalized sensitivities to (a) storativity, and (b) transmissivity at $r=1,5,10 \mathrm{~m}\left(\mathrm{~T}=600 \mathrm{~m}^{2} / \mathrm{d}, \mathrm{S}=\right.$ $0.0001, Q=2500 \mathrm{~m}^{3} / \mathrm{d}$ )
In terms of parameter estimation, the absolute magnitude of a sensitivity, not its signed value, is of importance. In the following discussion, when the word sensitivity is used, it usually means the absolute magnitude of sensitivity.

\section{Sensitivity Features of Aquifer Parameters in Theis Equation}

Sometimes analytical formulas for the head or drawdown can be found for simple models. In many of these cases, finding convenient analytical expressions for the sensitivity coefficients is also possible. As an example, consider the Theis equation. It describes radial confined groundwater flow towards a pumping well with negligible well storage in a homogeneous, isotropic aquifer of infinite areal extent:

$$
\mathrm{s}=\frac{\mathrm{Q}}{4 \pi \mathrm{T}} \mathrm{W}(\mathrm{u})
$$

where

$$
W(u)=\int_{u}^{\infty} \frac{e^{-x}}{x} d x \text { and } u=\frac{r^{2} S}{4 T t}
$$

$\mathrm{Q}$ is the pumping rate; $\mathrm{s}$ is drawdown at radial distance $\mathrm{r}$ at time $t$; and $W(u)$ is the well function.

The normalized sensitivities can be obtained by taking the derivative of the Theis equation with respect to $\mathrm{T}$ and $\mathrm{S}$ (McElwee and Yukler, 1978):

$$
\begin{gathered}
U_{T}^{\prime}=T \frac{\partial s}{\partial T}=-\frac{Q}{4 \pi T}\left[W(u)-e^{-u}\right] \\
U_{S}^{\prime}=S \frac{\partial s}{\partial S}=-\frac{Q}{4 \pi T} e^{-u}
\end{gathered}
$$

Figure 1 shows how $U_{T}^{\prime}$ and $U^{\prime}$ s change with time and space. Initially, $U_{\text {s }}$ increases rapidly. After a short time, it increases little and then becomes almost constant. In the very early stages, like $U_{S}^{\prime}, U_{T}^{\prime}$ increases with time, but the increase rate is not so significant as for $U_{S}^{\prime}$. Unlike $U_{S}^{\prime}, U_{T}^{\prime}$ will not tend to a constant value, although the changing rate becomes smaller and smaller with increasing time. Figure 1 also shows an observation well nearer the pumping well always shows larger sensitivity of parameters. Therefore, such a well can better define the aquifer parameters in an idealized aquifer. Figure 2 shows how $U_{T}^{\prime}$ and $U_{S}^{\prime}$ change with distance for different times. In general, for a particular observation well, longer pumping time leads to larger sensitivities.

\section{Sensitivity Analysis Using Radial Numerical Flow Model}

A numerical model can be easily modified for sensitivity analysis, and the same computer code used for the flow equation can be used for the sensitivity equations (McElwee, 1987). In this section, it will be demonstrated how a numerical model in terms of drawdown (or head) can be modified into a model in terms of sensitivity analysis of transmissivity, storativity, and well storage for a large-diameter pumping well. 
For confined, radial flow of ground water to a pumping well, the flow can be represented by the following equation:

$$
\mathrm{T} \frac{\partial^{2} \mathrm{~s}}{\partial \mathrm{r}^{2}}+\frac{\mathrm{T}}{\mathrm{r}} \frac{\partial \mathrm{s}}{\partial \mathrm{r}}=\mathrm{S} \frac{\partial \mathrm{s}}{\partial \mathrm{t}}
$$

with

$$
\left.\begin{array}{ll}
s(r, 0)=0 & r_{w} \leq r<\infty \\
s(\infty, t)=0 & t>0 \\
\left.\frac{\partial s}{\partial r}\right|_{T_{W}}=\frac{-Q}{2 \pi r_{W} T} & t>0
\end{array}\right\}
$$

An equation for the sensitivity of drawdown to a parameter can be obtained by differentiating the above equation and corresponding initial and boundary conditions with respect to that parameter. For example, for the sensitivity of drawdown to transmissivity, the sensitivity equation can be obtained as:

$$
\mathrm{T} \frac{\partial^{2} \mathrm{U}_{\mathrm{T}}}{\partial \mathrm{r}^{2}}+\frac{\mathrm{T}}{\mathrm{r}} \frac{\partial \mathrm{U}_{\mathrm{T}}}{\partial \mathrm{r}}=\mathrm{S} \frac{\partial \mathrm{U}_{\mathrm{T}}}{\partial \mathrm{t}}-\left(\frac{\partial^{2} \mathrm{~S}}{\partial \mathrm{r}^{2}}+\frac{1}{\mathrm{r}} \frac{\partial \mathrm{s}}{\partial \mathrm{r}}\right)
$$

with

$$
\left.\begin{array}{ll}
U_{T}(r, 0)=0 & r_{W} \leq r<\infty \\
U_{T}(\infty, t)=0 & t>0 \\
\left.\frac{\partial U_{T}}{\partial r}\right|_{r_{W}}=\frac{-Q}{2 \pi r_{W} T^{2}} & t>0
\end{array}\right\}
$$
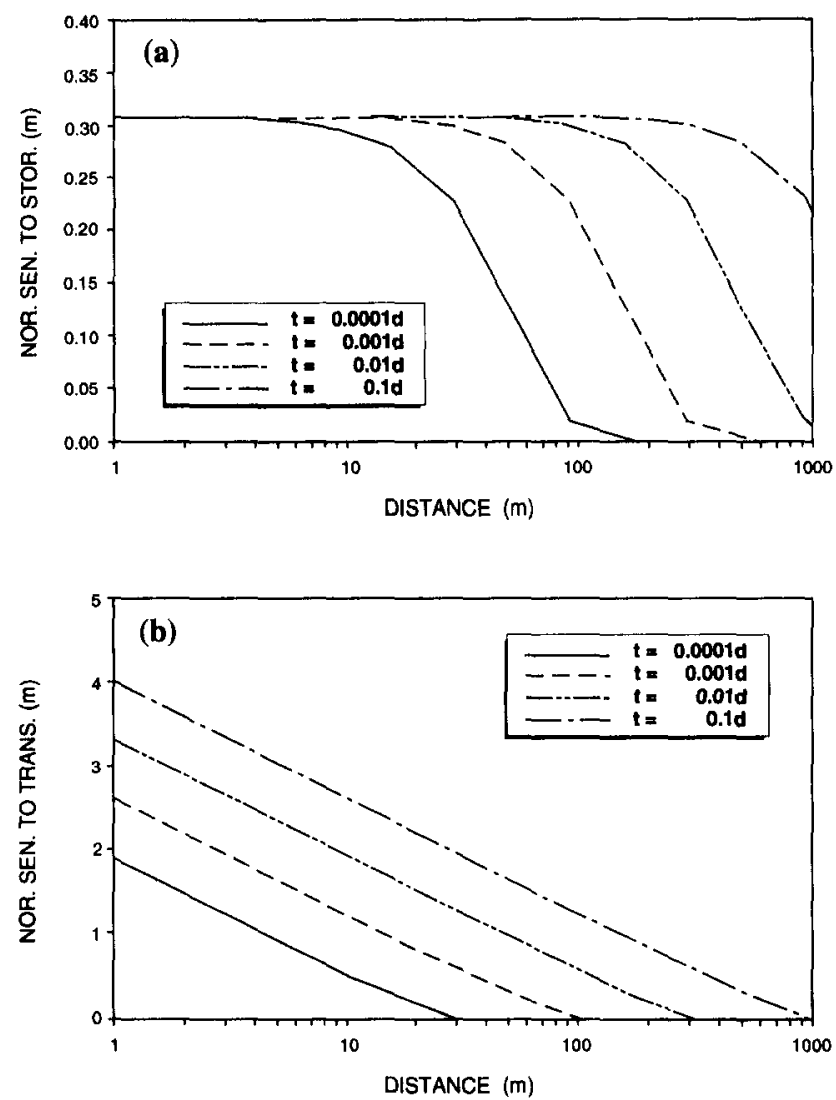

Fig. 2. Spatial change in normalized sensitivities to (a) storativity, and (b) transmissivity at different time $\left(\mathrm{T}=600 \mathrm{~m}^{2} / \mathrm{d}, \mathrm{S}=\right.$ $0.0001, Q=2500 \mathrm{~m}^{3} / \mathrm{d}$ ).
These equations have the same form as the drawdown equations [equations (8) and (9)] except for terms involving derivatives of $\mathbf{s}$. However, $s$ is known from the solution of the drawdown equation. Therefore, equations (10) and (11) can be solved with the same numerical model.

Similarly, the sensitivity equation of storativity can be obtained as

$$
\mathrm{T} \frac{\partial^{2} \mathrm{U}_{\mathrm{s}}}{\partial \mathrm{r}^{2}}+\frac{\mathrm{T}}{\mathrm{r}} \frac{\partial \mathrm{U}_{\mathrm{s}}}{\partial \mathrm{r}}=\mathrm{S} \frac{\partial \mathrm{U}_{\mathrm{s}}}{\partial \mathrm{t}}+\frac{\partial \mathrm{s}}{\partial \mathrm{t}}
$$

with

$$
\left.\begin{array}{ll}
U_{s}(r, 0)=0 & r_{w} \leq r<\infty \\
U_{s}(\infty, t)=0 & t>0 \\
\left.\frac{\partial U_{s}}{\partial r}\right|_{r_{w}}=0 & t>0
\end{array}\right\}
$$

The main concern in the present study is the well storage, the feature of which can be represented by well radius. The sensitivity and normalized sensitivity of drawdown to well radius can be defined in the same way as those of transmissivity and storativity:

$$
\mathrm{U}_{\mathrm{r}_{w}}=\frac{\partial \mathrm{s}}{\partial \mathrm{r}_{\mathrm{w}}}, \quad \mathrm{U}_{\mathrm{r}_{\mathrm{w}}}^{\prime}=\mathrm{r}_{\mathrm{w}} \frac{\partial \mathrm{s}}{\partial \mathrm{r}_{\mathrm{w}}}
$$

The drawdown equation can also be modified to a sensitivity equation in terms of $r_{w}$ by differentiating equations (8) and (9) with respect to $r_{w}$ :

$$
\mathrm{T} \frac{\partial^{2} \mathrm{U}_{\mathrm{r}_{w}}}{\partial \mathrm{r}^{2}}+\frac{\mathrm{T}}{\mathrm{r}} \frac{\partial \mathrm{U}_{\mathrm{r}_{w}}}{\partial \mathrm{r}}=\mathrm{S} \frac{\partial \mathrm{U}_{\mathrm{r}_{w}}}{\partial \mathrm{t}}
$$

with

$$
\begin{array}{ll}
U_{r_{w}}(r, 0)=0 & r_{w} \leq r \\
U_{r_{w}}(\infty, t)=0 & t>0 \\
\left.\frac{\partial U_{r_{w}}}{\partial r}\right|_{t_{w}}=\frac{-Q}{2 \pi r_{w}{ }^{2} T} & t>0
\end{array}
$$

\section{Analyses and Discussion}

For the present study, the radial numerical flow model of Rushton and Chan (1976), which is specially designed for use in pumping-test analysis, is modified for sensitivity analysis in a large-diameter well. Details of the modifications are discussed in Jiao (1993).

The hypothetical aquifer for this study has parameters $\mathrm{T}=650 \mathrm{~m}^{2} / \mathrm{d}$ and $\mathrm{S}=0.0001$, the initial head is $32 \mathrm{~m}$ above the bottom of the aquifer, the pumping rate is $2500 \mathrm{~m}^{3} / \mathrm{d}$, the test lasts 0.3 day, and the observation well is located at $r=5$ m.

\section{Sensitivity of Parameters Changing with Time}

Figure 3 shows how normalized sensitivities of drawdown to well radius, storativity, and transmissivity change with time for well radii of $0.5,0.05$, and $0.005 \mathrm{~m}$. Figure 3 (a) shows how the sensitivity of drawdown to well radius changes with time for the three well radii. The sensitivity for $r_{w}=0.5 \mathrm{~m}$ is by far the largest; for $r_{w}=0.005 \mathrm{~m}$ it is so small that it cannot be depicted on the same scale. Figure 3(a) 
shows that a complete sensitivity-time curve is bell-shaped in the semilog coordinates, such as the one for $r_{w}=0.5 \mathrm{~m}$ which reaches a maximum at about 0.0016 day and falls to near zero by 0.1 day. This means that the influence of the well storage only covers over a limited period.

The change in sensitivity seems related to the well storage being abstracted with time. The bottom of the aquifer is $32 \mathrm{~m}$ from the initial ground-water head. The total well storage when $r_{w}=0.5 \mathrm{~m}$ is $\pi \times 0.5^{2} \times 32=25.13 \mathrm{~m}^{3}$. The pumping rate is $2500 \mathrm{~m}^{3} / \mathrm{d}$. After 0.0016 day, a volume of water equivalent to $16 \%$ of the well storage is pumped from the well. Table 1 lists the time and the water pumped (expressed as the percentage of water storage). When the pumped water is about $2 \%$ of the well storage, the sensitivity of drawdown to $r_{w}$ begins to increase rapidly [Figure 3(a)]. At 0.0016 day, about $16 \%$ of the well storage has been consumed. This is equivalent to a column of water of about
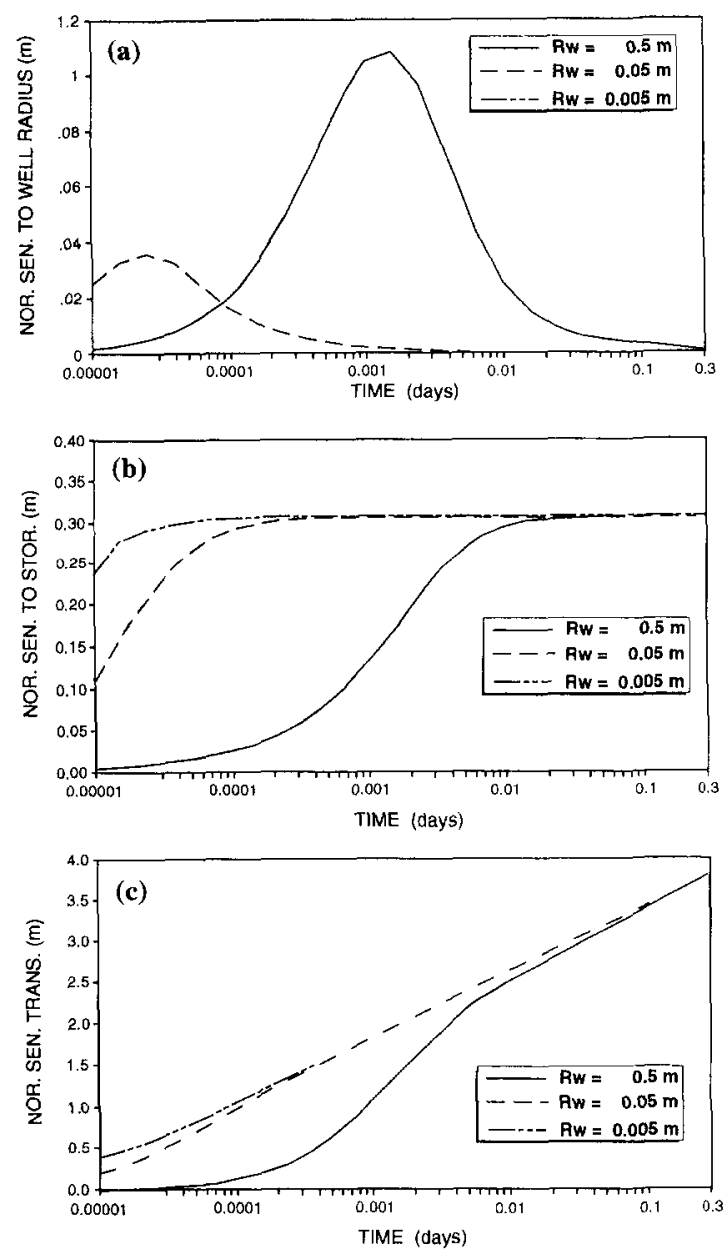

Fig. 3. Temporal change in normalized sensitivities of drawdown at $r=5 \mathrm{~m}$ to (a) well radius, (b) storativity, and (c) transmissivity for different well radii $\left(r_{w}=0.5,0.05,0.005 \mathrm{~m}\right) .\left(T=650 \mathrm{~m}^{2} / \mathrm{d}\right.$, $\left.S=0.0001, Q=2500 \mathrm{~m}^{3} / \mathrm{d}\right)$.

Table 1. Pumping Time and Water Pumped Equivalent to Percentage of Well Storage for $r_{w}=0.5 \mathrm{~m}$

\begin{tabular}{llllll}
\hline Time (days) & 0.0001 & 0.0002 & 0.0016 & 0.005 & 0.01 \\
Equivalent water (\%) & 1 & 2 & 16 & 50 & 99 \\
\hline
\end{tabular}

$5 \mathrm{~m}$ in the well; a considerable head difference exists between the well and the aquifer. After that time, the aquifer is significantly disturbed and aquifer features start to play an important role in the drawdown in the observation well. At about 0.01 day, an amount equivalent to $99 \%$ of the well storage has been pumped. After that time, the sensitivity of drawdown at the observation well at $r=5 \mathrm{~m}$ is effectively insensitive to the well radius.

Figure 3(b) shows the corresponding sensitivity of drawdown to storativity. Compared to the behavior of parameter sensitivity in the Theis aquifer, when the well radius is very small, the curve of sensitivity has very much the same shape as that in the Theis equation [Figure 1(a)]. When the well radius becomes large, the curve has a sigmoid form. At the beginning of pumping, most of the water is pumped from the well storage, only very limited water is drawn from the aquifer, and the drawdown is dependent mainly on the drainage of the well storage and is therefore not sensitive to the aquifer storage. The sensitivity in the case of large-diameter wells is significantly influenced by the well storage. Taking the case where $r_{w}=0.5 \mathrm{~m}$ for example, the sensitivity at the early stages is very small when most of the pumping water is from the well storage. At about 0.0016 day, when the well storage has been largely consumed and the sensitivity of well radius approaches a maximum, the slope of the storativity-sensitivity curve is the greatest. After that, the sensitivity to storativity continues to increase. When the sensitivity to well radius approaches zero, the sensitivity to storativity becomes almost constant. The behavior of the drawdown to storativity for well radius of $0.005 \mathrm{~m}$ is very much like that of the Theis aquifer [Figure 1(a)]. If a well diameter of $0.005 \mathrm{~m}$ can be practically regarded as infinitely small and the sensitivity behavior can be regarded as standard, then for a well with a diameter of $0.5 \mathrm{~m}$, it will take about 0.06 day (which is about one and a half hours) for the response of sensitivity to storativity at $5 \mathrm{~m}$ to become normal. In practice, some wells may have a radius as large as $2.5 \mathrm{~m}$ (Rushton and Holt, 1981). In this case, the sensitivity of drawdown to storage may be significantly reduced for several hours within tens of meters.

Figure 3(c) shows how the sensitivity of drawdown to transmissivity changes with time. Generally speaking, the influence of well storage on the sensitivity of transmissivity is much smaller than that of storativity. However, in the initial stages, the sensitivity of transmissivity when $r_{w}=0.5$ $m$ shows a similar pattern to that of storativity.

Comparison of the values of the normalized sensitivity to aquifer parameters and well radius indicates that the sensitivity to aquifer storativity is always very small, much smaller than that of well radius. This means that during the early stages, the sensitivity of the storativity may be so overshadowed by the well storage that it is very difficult to estimate aquifer storativity. However, the sensitivity of transmissivity is larger than that of the well storage over most of the time, and it significantly increases with time. It can be expected that, although storativity may be considerably influenced by well storage, transmissivity may still be reasonably well estimated even if the well radius is fairly large. 
Table 2. Maximum Normalized Sensitivity of Storativity and Distance at Which It Is Achieved Change with Well Radius at 0.001 Day

\begin{tabular}{llcccc}
\hline $\mathrm{r}_{\mathrm{w}}(\mathrm{m})$ & 0.1 & 0.3 & 0.5 & 1.0 & 2.0 \\
Distance $\mathrm{r}(\mathrm{m})$ & 1.8 & 16.9 & 28.0 & 31.6 & 35.6 \\
Max. U's(m) & 0.30 & 0.23 & 0.14 & 0.05 & 0.02 \\
\hline
\end{tabular}
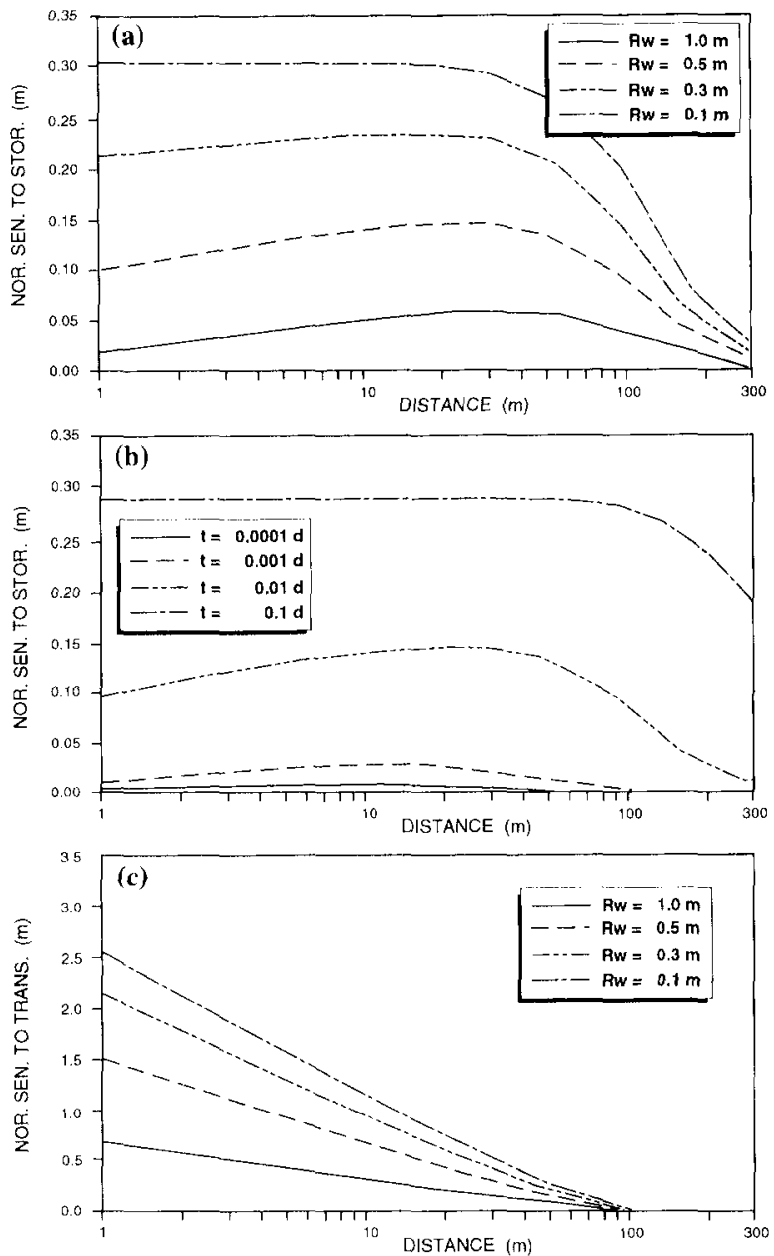

Fig. 4. Sensitivities of drawdown to aquifer parameters change with distance: (a) U's changes with well radius, (b) U's changes with time, and (c) $U_{T}^{\prime}$ changes with radius.

\section{Change in Parameter Sensitivity with Distance from Pumping Well}

In the previous discussion of the sensitivity behavior of the Theis equation, it was shown that the sensitivities of both transmissivity and storativity become larger when the observation well is closer to the pumping well (Figure 1) and that observation wells close to the pumping well will give better definition of transmissivity and storativity (Bohling et al., 1990).

Figure 4(a) shows how the sensitivity of drawdown to storativity changes with distance from the pumping well with well radii. Compared with the Theis equation [see Figure 2(a)], the sensitivity of drawdown to storativity displays a significantly different behavior, especially when the well radius is large. Instead of being gradually reduced with distance, the (absolute) sensitivity gradually increases with distance until reaching a maximum, beyond which it gradually decreases. This implies that, in terms of aquifer parame- ter estimation, the best location for taking drawdown readings should be at least a few meters away from the pumping well; the particular distance depends on the well radius. This is quite different from pumping tests in which well storage can be ignored.

At a particular time, the distance at which the sensitivity reaches its maximum changes with well radius. This is shown in Table 2 . Taking the sensitivity of storativity for $\mathrm{r}_{\mathrm{w}}=0.5$ as an example: it achieves the maximum of $0.14 \mathrm{~m}$ at a distance of $28 \mathrm{~m}$ after pumping for 0.001 day. This implies that the most informative reading of drawdown in terms of parameter estimation at 0.001 day should be taken at $28 \mathrm{~m}$ from the pumping well.

For a particular observation well, the maximum sensitivity of storativity also changes with time. Figure 4 (b) shows the sensitivity to storativity at $5 \mathrm{~m}$ from the pumping well of a radius of $0.5 \mathrm{~m}$ after pumping of $0.0001,0.001,0.01$, 0.1 day. The curve for 0.01 day clearly shows the existence of a maximum. When $t=0.1$ day, the pattern approaches the same shape as the sensitivity-time curve of the Theis equation [Figure 2(a)], although the magnitude of the sensitivity is still smaller than it would be in the case of the Theis equation.

Although the sensitivity of storativity shows complicated patterns in time and space for a large-diameter well, the pattern of the sensitivity of transmissivity is much simpler [Figure 4(c)]. Basically, it is similar to that of the Theis equation [Figure 2(b)], except that the absolute values of sensitivity are reduced because of well storage.

\section{Influence of Well Radius on Parameter Estimation}

Traditionally, most pumping tests are analyzed by analytical solutions and the well storage has to be ignored because of the difficulties of including its effect into the solutions. However, the radial numerical model can readily include this factor. The effect of well storage on parameter estimation will now be investigated.

When the well radius is $0.0005 \mathrm{~m}$, the well storage is thought to be negligible. Accordingly, the model with this well radius will be used as the basis of comparison. Different sets of drawdown data are created by running the model with well radii of $0.005,0.05$, and $0.5 \mathrm{~m}$. Using these data as "observed" data, different sets of parameters can be estimated by fitting the data using the radial flow model with the well radius of $0.0005 \mathrm{~m}$. For this study, an automatic fitting technique, the Gauss-Newton method [for details see Jiao (1993)] is used. In this way, the influence of well radius on parameter estimation can be investigated. For this discussion, the "true" parameters are $\mathrm{T}=650 \mathrm{~m}^{2} / \mathrm{d}$ and $\mathrm{S}=$ 0.0001 , the pumping duration is 0.3 day, the pumping rate is $2500 \mathrm{~m}^{3} / \mathrm{d}$, and the observation well is $5 \mathrm{~m}$ from the center of the abstraction well. The estimated parameters corresponding to different radii are presented in Table 3. It is seen that, when the well radius is $0.005 \mathrm{~m}$, the well storage is very small and does not cause much error in the estimated parameter values. However, when the radius is increased to $0.05 \mathrm{~m}$, the error becomes significant. Although the error in transmissivity is still less than $10 \%$, the estimate of storativity has been almost doubled. When the well radius is increased to $0.5 \mathrm{~m}$, the estimated values are too erroneous to represent 
Table 3. Estimated Parameters Change with Well Radius

\begin{tabular}{|c|c|c|c|c|}
\hline \multirow{2}{*}{$\begin{array}{l}\text { Well radius } \\
\text { (meters) }\end{array}$} & \multicolumn{2}{|c|}{ Transmissivity $\left(\mathrm{m}^{2} / \mathrm{d}\right)$} & \multicolumn{2}{|c|}{ Storativity } \\
\hline & $T$ & Error $(\%)$ & $10^{4} \mathrm{~S}$ & Error (\%) \\
\hline 0.0005 & 650.00 & 0.0 & 1.00 & 0 \\
\hline 0.005 & 648.42 & -0.2 & 1.02 & +2 \\
\hline 0.05 & 597.47 & -8.1 & 1.95 & +95 \\
\hline 0.5 & 400.95 & -38.3 & 3.60 & +350 \\
\hline
\end{tabular}

Table 4. Correlation Coefficients of the Sensitivities of Transmissivity and Storativity Change with Well Radii

\begin{tabular}{lllll}
\hline Well radius $(\mathrm{m})$ & 0.0005 & 0.005 & 0.05 & 0.5 \\
Correlation coefficient & 0.716 & 0.741 & 0.917 & 0.995
\end{tabular}

the "true" parameters. For a test well with radius of about 2 $\mathrm{m}$, which is typical of most of the domestic wells in the Third World, it can be imagined that, without including the effect of well storage, no reasonable parameter estimation can be achieved at least from the readings of an observation well 5 $\mathrm{m}$ away within 0.3 day of pumping.

When the storage of a large-diameter well is ignored, the error in storativity is about 10 times the error in transmissivity. This is because the well storage is lumped into the aquifer storage, so the estimated storage coefficient is exaggerated.

\section{Correlation Between Sensitivities of Transmissivities and Storativity}

In terms of parameter estimation, it is generally required that different parameters are not correlated. If there is a close correlation between different parameters, it is difficult to estimate them independently because discrepancies in one parameter may be lumped into the other. The correlation between the sensitivity of transmissivity and storativity for a large-diameter well will now be examined.

It can be seen from Figures 3(b) and (c) that the similarity or correlation between the sensitivities to transmissivity and storativity is very high when the well radius is large. Correlation coefficients between the sensitivities of transmissivity and storativity, calculated for different well radii, are listed in Table 4. The correlation increases with increasing well radius. This will make it difficult to estimate the two parameters independently. Therefore, even if the well storage can be adequately represented in the numerical model, in terms of parameter estimation, a large-diameter well will tend to produce uncertainties in parameter estimation and should thus be avoided.

\section{Field Example}

A well-documented test in a confined aquifer was carried out in South India. A cross section at the test site is shown in the inset of Figure 5. The abstraction rate was 691 $\mathrm{m}^{3} / \mathrm{d}$ and continued for 135 minutes ( 0.0938 day). Readings of drawdown in an observation well at a distance of $14.55 \mathrm{~m}$ were plotted in Figure 5. The radius of the pumping well is about $2.4 \mathrm{~m}$. The parameters were estimated to be $\mathrm{T}=26.5$ $\mathrm{m}^{2} / \mathrm{d}$ and $\mathrm{S}=0.0008$ (Rushton and Holt, 1981).

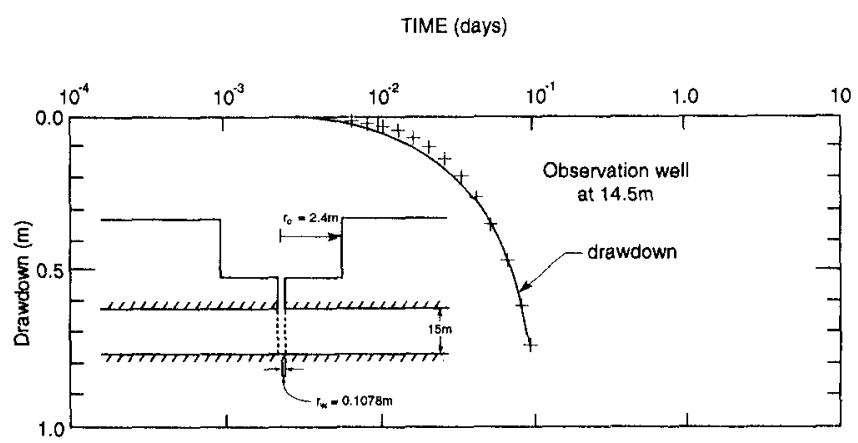

Fig. 5. Pumping test in a confined aquifer in South India. Crosses represent field observed drawdown in observation well, fill lines the numerical model (after Rushton and Holt, 1981).
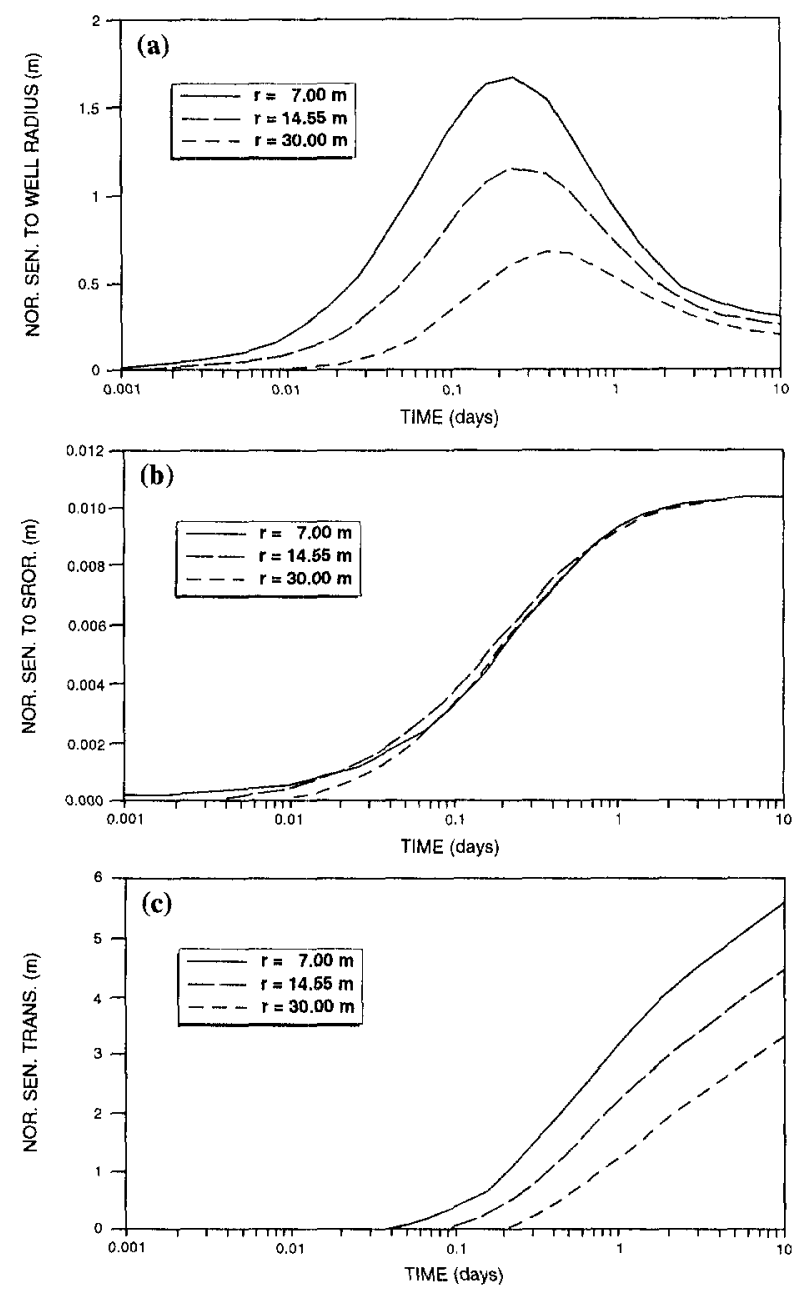

Fig. 6. Temporal changes in normalized sensitivities of drawdown at $r=7,14.55$, and $30 \mathrm{~m}$ to (a) well radius, (b) storativity, and (c) transmissivity. $\left(T=26.5 \mathrm{~m}^{2} / \mathrm{d}, \mathrm{S}=\mathbf{0 . 0 0 0 8}\right)$.

Using the approach discussed in this paper, the sensitivity features of parameters in this example will now be examined. Figure 6 shows how normalized sensitivities of drawdown to aquifer parameters and well radius change with time for different radius distances. The sensitivities to well storage decrease appreciably with radial distance. For all the three wells, the sensitivities to well storage approach maximum values between 0.1 and 1 day and then considerably decrease with time. The actual observation period was 


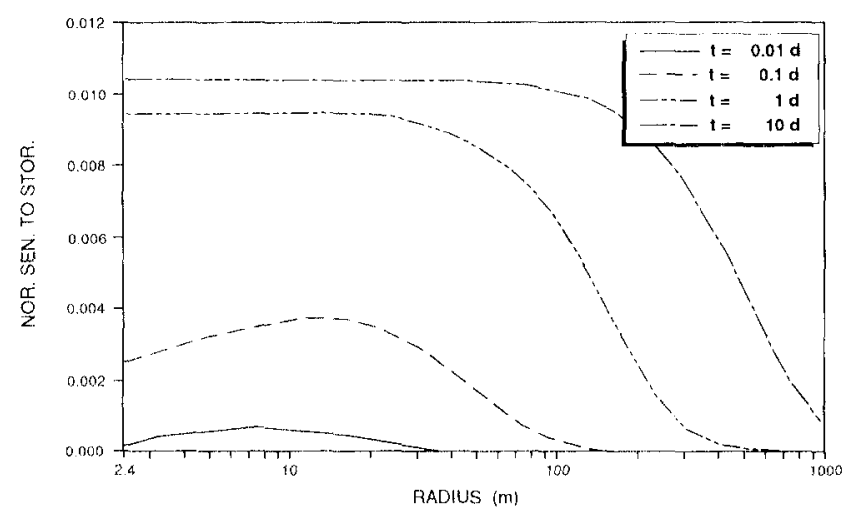

Fig. 7. Spatial changes in normalized sensitivities of drawdown to storativity for different observation times. $\left(\mathrm{T}=26.5 \mathrm{~m}^{2} / \mathrm{d}, \mathrm{S}=\right.$ 0.0008).

shorter than 0.1 day, during which the sensitivities of transmissivity, especially storativity, are much smaller than that of well storage. The influence of aquifer parameters therefore may be overshadowed by the influence of well storage. This may cause uncertainty in the estimated values. If the test period increased from 0.1 day to 1 day, Figure 6 shows that both the sensitivities of storativity and transmissivity would increase significantly. But this also corresponds to the period in which the sensitivity of well storage approaches maximum values. In order to reduce the influence of well storage and better define the aquifer parameters, it seems therefore that the test time should be considerably increased to more than 1 day. An increase from 0.1 day to 1 day would not make much difference.

As also shown in Figure 6, compared to the change in parameter sensitivities with distance, the change in the sensitivity of well storage (and therefore its influence on parameter estimation) with distance is more significant. An obscrvation well at a more distant location, where the influence of the well storage is much smaller but the sensitivity of aquifer parameters is still reasonably large, would have better defined the aquifer parameters.

Figure 7 shows how the sensitivity of aquifer storativity changes with distance for different time. After one day of pumping, the pattern of the change in sensitivity is similar to that of the Theis equation [see Figure 2(a)]. At time 0.1 day, the sensitivity approaches a maximum between 10 and $20 \mathrm{~m}$. Near the end of the present pumping period, the observation well seems at the right location because it provided the most informative readings at that time in terms of the storativity estimation.

\section{Conclusions}

With large well-bore pumping wells, the sensitivity behavior of aquifer parameters, especially storativity, is quite different from that represented in the Theis equation. The most informative measurements in terms of parameter estimation change with time and space. This is instructive for pumping-test design in a large-diameter well. The sensitivity of both transmissivity and storativity are reduced significantly when a large-diameter well is involved. This implies that the drawdown readings can be "noised" by the presence of a large-diameter well, significantly reducing the attendant data value in terms of estimating the aquifer parameters.

Comparing the sensitivities of well radius and aquifer parameters, the magnitude of storativity sensitivity is always relatively small. The influence of storativity can be overshadowed by the influence of well storage. It is therefore difficult to estimate the storativity when there is significant well storage. However, the transmissivity sensitivity is always relatively large. Consequently, although the estimated storativity may be erroneous, the transmissivity can still be estimated reasonably accurately in the presence of significant well storage effect.

A field example was used to demonstrate the importance of sensitivity features in pumping-test design in a large-diameter well. It is recommended that the sensitivity features of parameters should be analyzed by using some rough parameter values in advance of the actual test. This analysis may be instructive in choosing the location of observation wells and the period of pumping so that the aquifer parameters can be better defined. Even after the test has been conducted, it may still be helpful to perform sensitivity analysis using the estimated parameters to understand qualitatively the reliability of the estimated values.

It should be noted that even when well storage can be satisfactorily represented in the numerical model, it is better to avoid using a large-diameter well as a test well because the correlation between the sensitivities of transmissivity and storativity is very large for large-diameter wells. This causes uncertainties in estimating the parameters.

\section{Acknowledgment}

The authors appreciate stimulating discussions with C. D. McElwee. The comments by A.L.H. Gameson resulted in an improved text. Thanks also goes to L. A. Shumaker for assistance with the diagrams.

\section{References}

Bohling, G. C., C. D. McElwee, J. J. Butler, and W. Liu. 1990. User's Guide to Well Test Design and Analysis with SUPR PUMP Version 1.0. Kansas Geological Survey.

Jiao, J. J. 1993. Sensitivity features of aquifer parameters and their implications on parameter estimation. Ph.D. thesis, Dept. of Civil Engingineering, Univ. of Birmingham.

Knopman, D. S. and C. I. Voss. 1987. Behaviour of sensitivities in the one-dimensional advection-dispersion equation: Implications for parameter estimation and sampling design. Water Resour. Res. v. 23, no. 2.

Lai, R. Y., G. M. Karadi, and R. A. Williams. 1973. Drawdown at time-dependent flow rate. Water Resour. Bul. v. 9, no. 5, pp. $892-900$.

McElwee, C. D. 1987. Sensitivity analysis of groundwater models. In: Advances in Transport Phenomena in Porous Media. Ed. by J. Bear and M. Y. Corapcioglu. NATO Adv. Study Inst. Ser., Ser. E. v. 128, pp. 751-817.

McElwee, C. D. and M. A. Yukler. 1978. Sensitivity of groundwater models with respect to variations in transmissivity and storage. Water Resour. Res. v. 14, pp. 451-459.

Papadopulos, I. S. and H. H. Cooper. 1967. Drawdown in a well of large diameter. Water Resour. Res. v. 3, pp. 241-244.

Rushton, K. R. and Y. K. Chan. 1976. A numerical model for pumping test analysis. Proc. Instn. Civ. Engrs., Part 2. v. 61, pp. 281-296.

Rushton, K. R. and S. Holt. 1981. Estimating aquifer parameters for large diameter wells. Ground Water. v. 21, pp. 573-576. 